DOI: https://doi.org/10.24867/01KO06Popovic

\title{
OBRADA I DISTRIBUCIJA SATELITSKIH SNIMAKA UPOTREBOM APLIKACIJA OTVORENOG KODA
}

\section{ANALYSIS AND DISTRIBUTION OF SATELLITE IMAGES USING OPEN SOURCE APPLICATIONS}

\author{
Bojan Popović, Fakultet tehničkih nauka, Novi Sad
}

\section{Oblast - GEODEZIJA I GEOMATIKA}

Kratak sadržaj -U ovom radu ispitana je upotrebljivost aplikacija otvorenog koda $u$ daljinskoj detekciji kroz analizu satelitskih snimaka. Proizvodi dobijeni analizom su zatim distribuirani kroz GIS troslojnu arhitekturu.

Ključne riječi: Daljinska detekcija, Sentinel, GIS aplikacije otvorenog koda

Abstract - This paper examines the usability of open source applications in remote sensing through the analysis of satellite images. The products obtained by analysis were then distributed through a GIS three-layer architecture.

Keywords: Remote sensing, Sentinel, Open source GIS applications

\section{UVOD}

Sateliti za nadgledanje Zemlje su u posljednjih nekoliko godina postali glavna tema mnogih naučnih i inženjerskih disciplina jer pružaju izvor podataka o objektima, pojavama i fenomenima u Zemljinoj atmosferi i na njenoj površini. Sa pokretanjem Copernicus programa u sklopu Sentinel sistema omogućeno je besplatno preuzimanje satelitskih SAR (radarskih) i multispektralnih snimaka visoke prostorne rezolucije svakih nekoliko dana. Sentinel-2 sistem satelita (2A i 2B) sa MSI (Multispectral Instrumen) bilježe energiju refleksije u 13 spektralnih bendova. Zbog spektralne raznovrsnosti Sentinel-2 senzora, ova vrsta snimaka našla je primjenu najviše u poljoprivredi, šumarstvu i analizama prirodnih katastrofa.

Upravo zbog velikog potencijala koji ovi snimci imaju, potrebno je obezbijediti odgovarajuće softverske alate za njihovu obradu. Erdas Imagine i ENVI su dva najpoznatija softvera za obradu daljinski detektovanih podataka koji se koriste godinama. Oba softvera nude veliki broj opcija za obradu snimaka i ekstrakciju informacija iz ove vrste podataka. Međutim, oba softvera su komercijalna i neophodno je kupiti licencu za njihovo korišćenje.

U posljednjih nekoliko godina razvijeno je nekoliko softverskih rješenja za analizu i manipulaciju satelitskim snimcima otvorenog koda. U većini slučajeva riječ je o volonterskim projektima u koje se može uključiti bilo ko.

\section{NAPOMENA:}

Ovaj rad proistekao je iz master rada čiji mentor je bio dr Dušan Jovanović, docent.
Pošto je izvorni kod programa otvoren, svako može da ga vidi, mijenja i prilagodi sopstvenim potrebama.

Od sredine 2000-ih GIS aplikacije otvorenog koda su počele da privlače pažnju preduzeća i vladinih agencija širom svijeta. Ipak, uvođenje ovakvog tipa aplikacija u poslovne procese ometa činjenica da u ovom trenutku ne postoji gotova metoda za prelazak na open source GIS rješenja, jer su u opštem slučaju u pitanju aplikacije za široki spektar primjene, i potrebno je izvršiti njihovo prilagođavanje za specifični tip poslova. Komercijalna rješenja s druge strane nude gotove pakete alata za usko specijalizovane oblasti sa odličnom korisničkom podrškom u njihovoj implementaciji [1].

Cilj ovog rada je demonstracija upotrebljivosti aplikacija otvorenog koda za obradu i distribuciju satelitskih snimaka na praktičnim primjerima. Opisan je postupak dobijanja referentnih rastera za detekciju zona za uzorkovanje zemljišta na osnovu vegetacionih indeksa, identifikacije i mapiranja vrsta drveća na području NP Fruška gora i mapiranje usjeva u opštini Bečej.

\section{DALJINSKA DETEKCIJA}

Daljinska detekcija predstavlja metodu prikupljanja informacija o objektu ili pojavi bez fizičkog kontakta sa njima. Daljinska detekcija se koristi u mnogim oblastima, uključujući geografiju, poljoprivredu, geodeziju i većinu naučnih disciplina na Zemlji (hidrologija, ekologija, okeanografija, glaciologija, geologija). Ona takođe ima vojne, obavještajne, komercijalne, ekonomske, planske i humanitarne primjene [2].

\subsection{Sentinel-2}

Sentinel-2 je misija za posmatranje Zemlje koju je razvila ESA u okviru programa Copernicus za obavljanje terestričkih posmatranja u cilju pružanja usluga kao što su monitoring šuma, otkrivanje promjena zemljišnih pokrivača i upravljanje prirodnim katastrofama.

Sentinel-2 obezbjeđuje multispektralne snimke visoke rezolucije Zemljine površine. Misija se sastoji iz dva satelita koji se nalaze $\mathrm{u}$ istoj orbiti na visini od $786 \mathrm{~km} \mathrm{i}$ pozicionirani su za $180^{\circ}$ jedan od drugog. Sentinel-2A je lansiran 23. juna 2015. godine, a Sentinel-2B 07. marta 2017.

Svaki od satelita Sentinel-2 misije ima optički instrument sposoban da snima u 13 spektralnih opsega: 4 benda na 10 $\mathrm{m}, 6$ bendova na $20 \mathrm{~m}$ i 3 benda na $60 \mathrm{~m}$ prostorne rezolucije. Širina orbitalne trake iznosi $290 \mathrm{~km}$. 


\subsection{Landsat}

Landsat program je najstariji program za prikupljanje satelitskih snimaka o Zemlji koji je i dalje operativan. Program je u nadležnosti NASE i United States Geological Survey (USGS). Prvi satelit, Landsat 1, je lansiran davne 1973. godine i do danas je lansirano još sedam generacija satelita od kojih je posljednji Landsat 8 (2013. godine). Svaka generacija satelita je donosila poboljšanja u pogledu spektralne, prostorne, radiometrijske i temporalne rezolucije. Trenutno su aktivni Landsat 7 i Landsat 8 sateliti. Landsat 8 nosi dva push-broom instrumenta: Operational Land Imager (OLI) i Thermal Infrared Sensor (TIRS).

OLI instrument mjeri energiju refleksije u vidljivom, blisko infracrvenom, i usko infracrvenom opsegu elektromagnetnog zračenja. Panhromatski snimci imaju prostornu rezoluciju $15 \mathrm{~m}$ a multispektralni $30 \mathrm{~m}$. Instrument obezbjeđuje veliku pokrivenost Zemljine površine orbitalnom trakom širine $185 \mathrm{~km}$.

Thermal Infrared Sensor (TIRS) mjeri temperaturu Zemljine površine u dva termalna benda upotrebom nove tehnologije koja se zasniva na kvantnoj fizici. Bendovi su prostorne rezolucije $100 \mathrm{~m}$.

\section{OBRADA SNIMAKA}

\subsection{Predprocesing}

Operacije predprocesinga, ponekad nazvane i operacijama obnavljanja i ispravaka slike, imaju za cilj ispravljanje radiometrijske i geometrijske distorzije podataka. Radiometrijske korekcije mogu biti neophodne zbog varijacija u osvjetljenju scene i geometrije pogleda, atmosferskih uslova, karakteristika senzora i uticaja šuma.

Predprocesing svih korištenih snimaka je izvršen u SNAP programskom paketu, tako što je prvo urađen resampling svih bendova na $10 \mathrm{~m}$ prostorne rezolucije i njihovo sječenje na oblik područja od interesa.

Dalja obrada je nastavljena u QGIS programu, gdje su pojedinačni bendovi svakog od snimaka spojeni u odgovarajuće fajlove opcijom Layer Stack iz SCP palete alata.

\subsection{Analiza stanja usjeva}

Najveću primjenu satelitski snimci su našli u poljoprivredi gdje se koriste za razne analize, klasifikacije i detekcije promjena na osnovu čega se razvila cijela jedna nova oblast u poljoprivredi nazvana precizna poljoprivreda.

Za područje analize izabrano je jedno poljoprivredno gazdinstvo u blizini Siriga. Analiza je rađena sa ciljem detektovanja zona za uzorkovanje zemljišta. Korišten je NDVI vegetacioni indeks izračunat na osnovu 3 satelitska snimka sa datumima akvizicije: 24.06.2017., 21.07.2017. i 03.08.2017.

NDVI predstavlja odnos razlike i zbira refleksije u blisko infracrvenom i crvenom opsegu elektromagnetnog zračenja. NDVI je izračunat u QGIS softveru upotrebom Raster calculator alata koji koristi GDAL biblioteku.

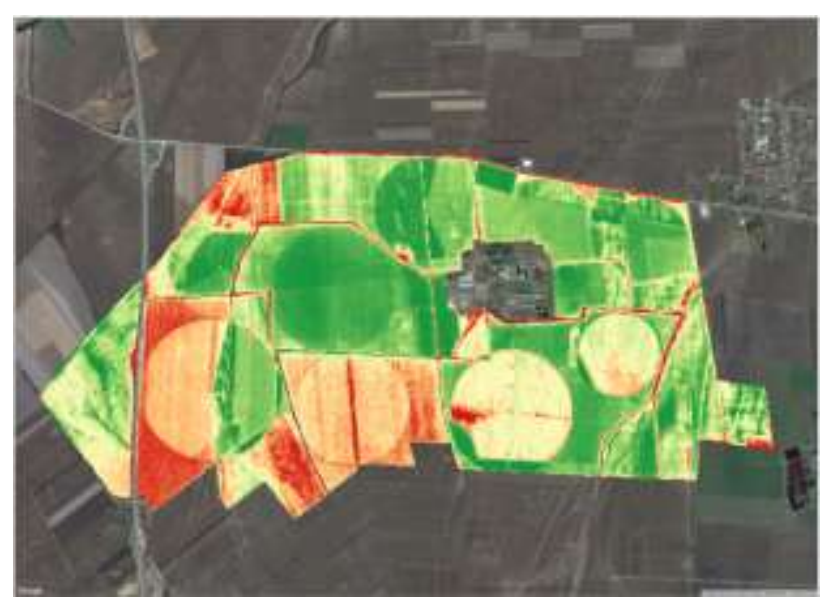

Slika 1. Rezultati NDVI indeksa za 21.07.2017.

\subsection{Klasifikacija vrsta drveća}

Šuma je najveći kopneni ekosistem biljnih i životinjskih vrsta $\mathrm{i}$ kao takva predstavlja jedan od najznačajnijih bioloških elemenata $u$ prirodi. Ona igra važnu ulogu $u$ proizvodnji kiseonika, dom je raznim biljnim i životinjskim vrstama i predstavlja glavni izvor jednog od najvažnijih prirodnih materijala, drveta. Za područje analize izabran je jedan dio NP Fruška gora.

Za identifikaciju vrsta drveća je korištena nadgledana klasifikacija upotrebom Minimum Distance algoritma. Minimum Distance klasifikacija se vrši tako što se spektralna udaljenost vektora osobina piksela i vektora srednjih vrijednosti određene klase računa kao Euklidsko rastojanje [3].

Cijeli postupak je obavljen korištenjem alata iz QGIS softverskog paketa. $\mathrm{Na}$ osnovu poznatih informacija o prostornom rasporedu klasa formiran je obučavajući skup koji sadrži spektralne potpise pojedinačnih klasa. Potpisi su prikupljeni za 11 klasa: Topola serotin; Crni orah; Grab; Srebrna lipa; Cer; Hrast kitnjak; Hrast lužnjak; Bagrem; Crni bor; Zemlja; i Niska vegetacija. Kako bi se eliminisao efekat „soli i bibera“ koristi se neki od algoritama za generalizaciju. U ovom slučaju korišten je Majority filter.

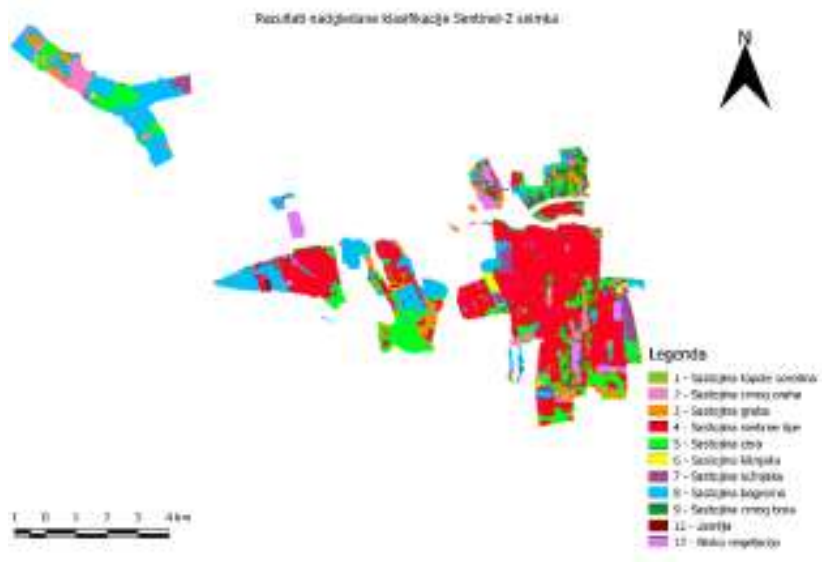

Slika 2. Rezultat klasifikacije vrsta drveća na području NP Fruška gora. 


\subsection{Mapiranje usjeva u opštini Bečej}

Pouzdane informacije o usjevima su neophodne radi poboljšanja poljoprivredne proizvodnje i umanjenja negativnih uticaja koje proizvodnja ostvaruje na okolinu. Za prikupljanje ovih informacija mogu se koristiti različite metode, ali najčešće daljinska detekcija sa satelitskim snimcima predstavlja najpouzdaniji i najlogičniji izbor.

Za testiranje upotrebljivosti Sentinel-2 multitemporalnih snimaka i Random Forest algoritma u procesu identifikacije i mapiranja usjeva izabrano je područje opštine Bečej. Izvršena je identifikacija 5 najzastupljenijih vrsta usjeva: kukuruz, pšenica, ječam, šećerna repa i lucerka.

Random Forest algoritam je nadgledani algoritam mašinskog učenja. Može se koristiti i za klasifikaciju i regresiju. U odnosu na parametarske klasifikatore (npr. Maximum Likelihood) mašinsko učenje ne počinje sa modelom podataka, već umjesto toga uči odnos između obučavajućeg skupa i ulaznih podataka. Random Forest klasifikator je agregacioni model, što znači da koristi izlaz iz različitih modela (stablo odluke) kako bi došao do rezultata, u našem slučaju do klase [4].

Zbog toga što se ova identifikacija zasniva na klasifikaciji multitemporalnih satelitskih snimaka, njihova integracija izvršena je na dva načina. U prvom načinu, svi spektralni bendovi svih pet snimaka spojeni su u jedan raster sa 50 slojeva (bendovi B1, B9 i B10 nisu korišćeni). Ovo je postignuto opcijom Layer Stack iz Semi-Automatic Classification Plugin dodatka u QGIS-u. Dobijeni raster je zatim klasifikovan pomoću Orfeo ToolBox (OTB) alata.

U drugom pristupu bendovi iz svakog snimka su spojeni u zasebne rastere čime je dobijeno pet rastera sa 10 spektralnih bendova. Svaki od tih rastera je posebno klasifikovan. Pošto u ovom slučaju postoji pet klasifikovanih rastera, alatom Fusion Of Classification u OTB-u su svi spojeni u jedan fajl.

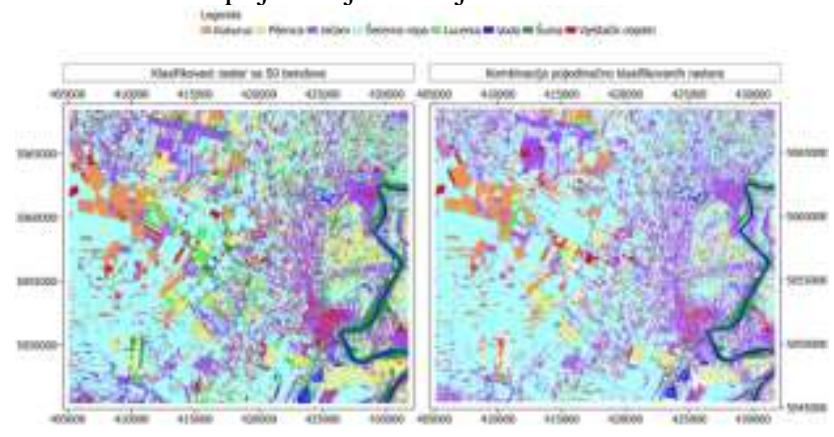

Slika 3. Rezultat Random Forest klasifikacije rastera sa 50 bendova lijevo i spajanjem pojedinačnih klasifikacija desno

\section{DISTRIBUCIJA DOBIJENIH PODATAKA}

$\mathrm{Za}$ sve gore navedene proizvode izvršena je njihova distribucija kroz troslojnu GIS arhitekturu, koja se sastoji od: Baze podataka sa sistemom za upravljanje bazom podataka; Servisnog sloja koji vrši publikaciju podataka iz baze u skladu sa OGC standardima (WFS, WMS, WCS); i Korisnički sloj, geoportal ili desktop aplikacija u kojoj se podaci prikazuju.

Za potrebe ovog rada korištena je PostgreSQL baza podataka sa PostGIS proširenjem. Svi rasteri su učitani u bazu uz pomoć raster2pgsql alata. Svaki raster je smješten u posebnu tabelu u bazi.

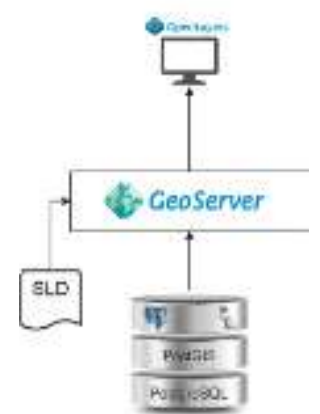

Slika 4. Troslojna GIS arhitektura

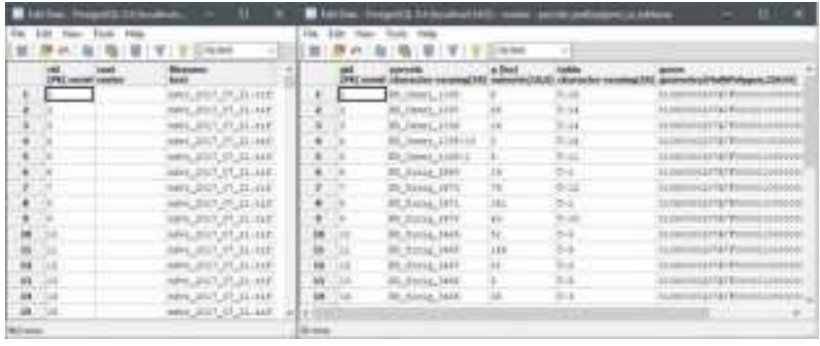

Slika 5. Tabele u bazi za raster NDVI 2017-07-21 lijevo $i$ pomoćne vektorske podatke desno

Radi lakše interpretacije rasterskih podataka, učitani su i pomoćni vektorski podaci koji će takođe biti publikovani na geoportal. U slučaj analize stanja usjeva, poljoprivredno gazdinstvo je parcele organizovalo u strukturu tabli. Jedan blok može da se nalazi na više katastarskih parcela $\mathrm{i}$ isto tako jedna parcela može da bude izdijeljena na više tabli. Zbog toga su publikovani i podaci koji se odnose na atribute vezane za table i parcele na tom području.

Svi podaci iz baze su publikovani na Geoserver gdje su im dodijeljeni odgovarajući stilovi upotrebom SLD (Styled Layer Descriptor).

Geoportal za prikaz podataka je formiran upotrebom HTML i JavaScript programskih jezika. Uz pomoć Geoservera kreirani su OGC servisi, gdje je za prikaz iskorišten WMS (Web Map Service) koji predstavlja obrađene rastere. Korišten je WMS umjesto WCS (Web Coverage Service) jer Open Layers 3 nema ugrađenu podršku za taj standard.

Svi rasterski i vektorski podaci su stilizovani za prikaz upotrebom SLD (Styled Layer Descriptor). SLD je XML šema specificirana od strane OGC (Open Geospatial Consortium) za stilizaciju prikaza slojeva mape. Koristi se za prikaz i rasterskih i vektorskih podataka.

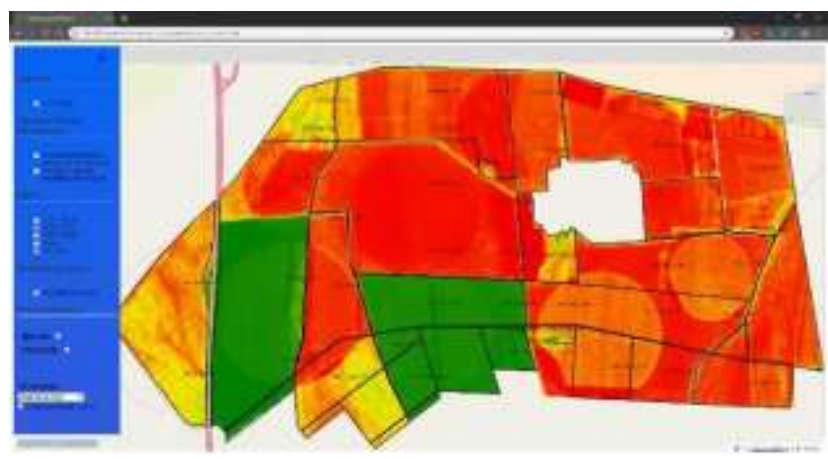

Slika 6. Prikaz NDVI rastera sa preklopljenim podacima o parcelama na geoportalu 


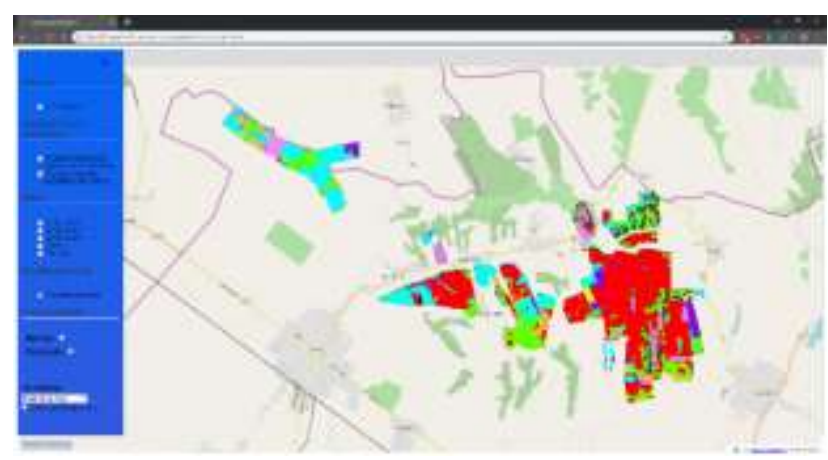

Slika 7. Prikaz rastera sa klasifikovanim vrstama drveća na geoportalu

\section{SEN2AGRI}

Sen2Agri je samostalni sistem za generisanje proizvoda na osnovu Sentinel-2 i Landsat 8 multispektralnih snimaka u toku sezone uzgoja usjeva za potrebe precizne poljoprivrede. Ovi različiti proizvodi se sastoje od: Mjesečne kompozicije površinske refleksije bez oblaka sa rezolucijom od 10 i $20 \mathrm{~m}$; Mjesečne binarne mape sa detekcijom obradivog zemljišta (pikseli imaju vrijednost 0 ili $1 \mathrm{u}$ zavisnosti od toga da li predstavljaju obradivo zemljište ili ne); Mape sa vrstama usjeva prostorne rezolucije $10 \mathrm{~m}$ za glavne vrste usjeva, dva puta u toku sezone; Periodične mape stanja vegetacije (NDVI i LAI vegetacioni indeksi) usjeva svaki put kada se zabilježi snimak bez oblaka.

Sen2Agri u potpunosti implementira GIS troslojnu arhitekturu, sa dodatkom modula koji služi za automatizaciju izvršavanja pojedinih procedura (Orchestrator).

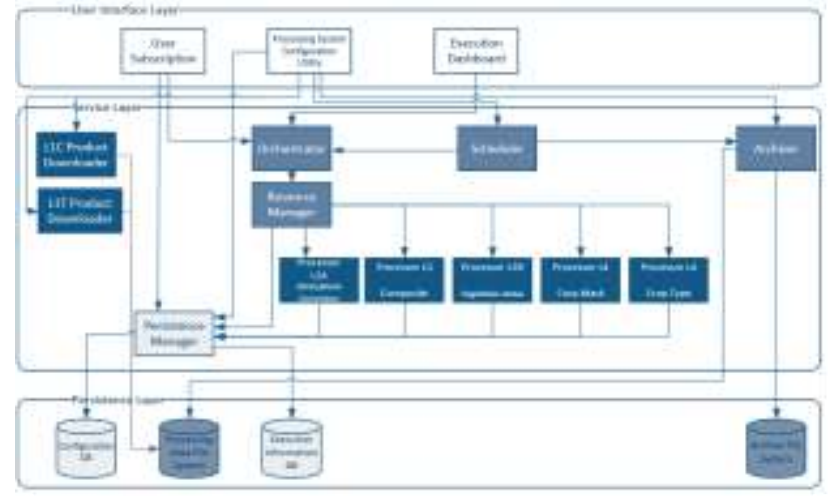

Slika 8. Arhitektura Sen2Agri sistema [5]

\section{ZAKLJUČAK}

U posljednjih deset godina zabilježen je veliki porast broja lansiranih satelita za snimanje Zemljine površine. Posljedica toga je generisanje terabajtnih arhiva podataka u vidu satelitskih snimaka koji pokrivaju Zemljinu površinu, u nekim slučajevima na dnevnom nivou. Ovi podaci u svom sirovom obliku nisu od velike upotrebljivosti ni za jednu naučnu ili privrednu granu. Međutim, informacije dobijene pravilnom obradom, analizom i ekstrakcijom podataka iz satelitskih snimaka predstavljaju značajan resurs za mnoge sisteme odlučivanja u privredi i nauci. U prošlosti softveri koji su korišteni za obradu daljinski detektovanih podataka su bili komercijalnog tipa i nisu bili dostupni svima.
Zahvaljujući volonterskim projektima pojedinaca i nekih institucija u posljednje vrijeme razvijen je veliki broj aplikacija otvorenog koda iz oblasti GIS-a i daljinske detekcije. Ovakvi sistemi, pored alata za obradu snimaka, omogućavaju korisnicima da razumiju algoritme i logiku alata koje koriste. Takav pristup omogućava usavršavanje i samog softvera i operatera koji ga koristi.

Glavne prednosti ovakvih aplikacija su skalabilnost, laka integracija sa ostalim alatima otvorenog koda, interoperabilnost postignuta kroz standardizaciju formata ulaznih i izlaznih podataka. Svoje glavne mane u vidu nepostojanja korisničke podrške ili odgovarajuće dokumentacije, nadoknađuje velikom zajednicom korisnika i programera koji konstantno unapređuju aplikaciju.

U ovom radu je dat pregled najčešće korišćenih GIS aplikacija otvorenog koda. Pokazano je da se na osnovu ovih alata može izvršiti obrada satelitskih snimaka i dobiti proizvod istog kvaliteta kao i sa komercijalnim programima. U radu su prikazani osnovni koraci predprocesinga snimaka $\mathrm{i}$ analiza za primjenu $\mathrm{u}$ poljoprivredi i šumarstvu jer se satelitski snimci najviše koriste u tim oblastima.

\section{LITERATURA}

[1] Jovanović, D., Popović, B. I Govedarica, M., Use Of Open Data And Applications In The Education Process, International Scientific Conference On Contemporary Theory And Practice In Construction Xiii - Stepgrad, Banja Luka, 2018.

[2] https://cyberleninka.ru/article/v/daljinska-detekcijakao-metod-prikupljanja-podataka-o-prostoru (pristupljeno u septembru 2018.)

[3] https://pdfs.semanticscholar.org/a963/6af0682c89 4eaa564acd1c7d2b87274826b1.pdf (pristupljeno u septembru 2018.)

[4] Breiman, L., Random Forests, Machine Learning, 45(1), pp.5-32, 2001.

[5] http://www.esa-sen2agri.org/wpcontent/uploads/Sen2Agri_SUM_v2.8.pdf pdf (pristupljeno u septembru 2018.)

\section{Kratka biografija:}

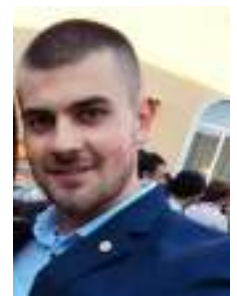

Bojan Popović rođen je u Doboju 1994. godine. Master studije na Fakultetu tehničkih nauka upisao je 2017. godine. Tokom master studija učestvovao je u izvođenju nastave kao demonstrator. Oblasti interesovanja su geoinformatika, daljinska detekcija i fotogrametrija. kontakt: bojanpop94@uns.ac.rs 